\title{
Critical appraisal of ceftaroline in the management of community-acquired bacterial pneumonia and skin infections
}

This article was published in the following Dove Press journal:

Therapeutics and Clinical Risk Management

23 March 2012

Number of times this article has been viewed

\section{Julian J Goodman}

Stanley I Martin

Division of Infectious Diseases, The Ohio State University,

Columbus, OH, USA
Correspondence: Stanley I Martin NI I 48 Doan Hall, 4I0W. I0th Ave, Columbus, $\mathrm{OH} 43210, \mathrm{USA}$

Tel + I 6142935666

Fax +I 6I4 2934556

Email stanley.martin@osumc.edu
Abstract: Ceftaroline is a novel broad-spectrum cephalosporin $\beta$-lactam antibiotic with activity against methicillin-resistant Staphylococcus aureus (MRSA) as well as multidrug-resistant Streptococcus pneumoniae among other routine Gram positive and Gram negative organisms. It has been approved by the US Food and Drug Administration for treatment of communityacquired bacterial pneumonia and acute bacterial skin and skin structure infections (ABSSSIs). Ceftaroline is approved for treatment of ABSSSI due to MRSA, however currently there are no data for pneumonia due to MRSA in humans. Herein we review the major clinical trials as well as ceftaroline microbiology, pharmacokinetics, and safety, followed by a look at further directions for investigation of this new agent.

Keywords: ceftaroline, pneumonia, skin infection

\section{Introduction to clinical applications of ceftaroline}

Ceftaroline fosamil (formerly T-91825) is the N-phosphorylated prodrug of ceftaroline (formerly PPI 0903M and TAK-499), a novel broad spectrum $\beta$-lactam antibiotic with activity against methicillin-resistant Staphylococcus aureus (MRSA) as well as Streptococcus pneumoniae with resistance to penicillin and other cephalosporins. ${ }^{1-3}$ Based on two Phase III studies in community-acquired bacterial pneumonia (CABP) ${ }^{4,5}$ and two Phase III studies in acute bacterial skin and skin structure infections (ABSSSIs), ${ }^{6,7}$ ceftaroline received approval from the US Food and Drug Administration in 2010 for treatment of CAPB due to $S$. pneumoniae (including cases with concurrent bacteremia), methicillin-sensitive S. aureus (MSSA), Haemophilus influenzae, H. parainfluenzae, Klebsiella pneumoniae, and Escherichia coli as well as ABSSSI due to MSSA, MRSA, S. pyogenes, S. agalactiae, S. dysgalactiae, S. anginosus group, Enterococcus faecalis (ampicillin-susceptible isolates only), E. coli, K. pneumoniae, K. oxytoca, and Morganella morganii. This article will discuss the trials resulting in this approval in further depth, as well as the mode of action, microbiology, pharmacokinetics, and safety and tolerability of ceftaroline, as well as advantages and disadvantages in comparison to alternate therapies.

\section{Clinical issues in the management of CABP and ABSSSI}

Community-acquired bacterial pneumonia

The FOCUS (ceFtarOline Community-acquired pneUmonia trial vS ceftriaxone in hospitalized patients) trials are two Phase III multicenter, randomized, double-blind 
trials comparing ceftaroline to ceftriaxone in CABP to demonstrate noninferiority. ${ }^{4,5}$, Patients with CAPB with Pneumonia Outcomes Research Team (PORT) scores of III or IV were randomized to receive either ceftaroline $600 \mathrm{mg}$ intravenously (IV) every 12 hours or ceftriaxone $1 \mathrm{~g}$ IV every 24 hours. Patients enrolled in either arm of FOCUS 1 also received two doses of clarithromycin $500 \mathrm{mg}$ orally in the first 24 hours. Treatment was given for 5 to 7 days. Exclusion criteria included PORT class I, II, or V; intensive care unit admission at baseline; CABP suitable for outpatient therapy; confirmed or suspected health care-associated pneumonia pathogen; infection with a pathogen known to be resistant to study medication or high risk for such; high risk for MRSA or with Gram-positive cocci in clusters on sputum Gram stain; infection due to atypical pathogen (Legionella, Mycoplasma, Chlamydophila spp.); prior antimicrobial therapy within 96 hours; creatinine clearance $\leq 30 \mathrm{~mL} / \mathrm{min}$; elevated transaminases or bilirubin or other manifestation of end-stage liver disease; neutropenia or thrombocytopenia; empyema; and immunocompromise (chronic steroids, acquired immunodeficiency syndrome, etc). The primary outcome was to determine noninferiority in clinical cure rates at a test-of-cure visit 8-15 days post therapy in the clinically evaluable and modified intention-to-treat (MITT) groups. Secondary outcomes included cure in microbiologically evaluable (ME) and microbiological modified intention-to-treat (mMITT) groups (meaning at least one pathogen was isolated), cure at end of therapy, microbiological outcome at test-of-cure visit, overall success rate at test-of-cure visit, clinical and microbiological response by pathogen at test-of-cure visit, clinical relapse at a late follow-up visit (21-35 days after discontinuing study drug), microbiological reinfection/recurrence, and safety. A total of 1240 patients were randomized of whom 1228 received any drug. 614 each received ceftaroline and ceftriaxone. The two groups were similar in terms of baseline demographics, severity of pneumonia, comorbidities, and prior antibiotic use.

The clinical cure rate in the evaluable population was $84.3 \%$ in the ceftaroline group versus $77.7 \%$ in the ceftriaxone group (difference $6.7 \%, 95 \%$ confidence interval [CI]: $1.6 \%-11.8 \%$ ). In the MITT group, cure rates were $82.6 \%$ and $76.6 \%$, respectively (difference 6\%, 95\% CI: 1.4\%-10.7\%). For ME patients, cure rates were $85.1 \%$ versus $75.5 \%$ (difference $9.7,95 \% \mathrm{CI}: 0.7 \%-18.8 \%$ ), and in the mMITT population, cure rates were $83.6 \%$ versus $75 \%$ (difference $8.7 \%$, 95\% CI: $0 \%-17.4 \%$ ). All of these rates met noninferiority criteria, and all save the mMITT group reached numerical significance for the superiority of ceftaroline. For patients with $S$. pneumoniae infection, the cure rate for ceftaroline was $85.5 \%$ compared with $68.6 \%$ with ceftriaxone (difference $16.9 \%$, no CI reported). For those with $S$. aureus infection including one patient with MRSA in the ceftriaxone arm, the cure rate was $72 \%$ versus $60 \%$ (difference $12 \%$, no CI reported). In bacteremic patients, cure rates were $71.4 \%$ for ceftaroline compared with $58.8 \%$ for ceftriaxone (difference $12.6 \%, 95 \%$ CI: $-17.6 \%-41.6 \%)$.

\section{Acute bacterial skin and skin structure infections}

In 2007, a Phase II randomized, observer-blinded trial of ceftaroline compared with vancomycin with or without aztreonam for ABSSSI was released. ${ }^{9}$ The primary outcome of this study was clinical cure rate at a test-of-cure visit; a blinded investigator determined cure as resolution of signs and symptoms of ABSSSI or improvement such that no further therapy was needed. This trial included 100 patients, 67 in the ceftaroline arm and 33 in the comparator arm. Those on ceftaroline received $600 \mathrm{mg}$ IV every 12 hours. Vancomycin was dosed at $1 \mathrm{~g}$ every 12 hours and aztreonam at $1 \mathrm{~g}$ every 8 hours. Patients were excluded if they had creatinine clearance $\leq 30 \mathrm{~mL} / \mathrm{min},>24$ hours of antimicrobials in the preceding 96 hours, known vancomycin- or aztreonamresistant pathogens including Pseudomonas aeruginosa or anaerobes, underlying osteomyelitis or septic arthritis, necrotizing fasciitis, human or animal bites, diabetic foot ulcers, gangrene, burns covering $>5 \%$ of the body, mediastinitis, or required surgical intervention that could not be performed within 48 hours of initiating therapy. The two groups were similar in baseline demographics, types of infection, and microbes isolated. Cure rates in evaluable patients in both arms were comparable.

This study was followed by the two CANVAS (CeftAroliNe Versus VAncomycin in Skin and Skin Structure Infections) trials, Phase III multicenter, randomized, double blind studies again comparing ceftaroline to vancomycin with aztreonam for ABSSSI to demonstrate noninferiority. ${ }^{6,7,10}$ In these identical trials patients with ABSSSI were randomized to receive ceftaroline $600 \mathrm{mg} \mathrm{IV}$ every 12 hours plus normal saline placebo or vancomycin $1 \mathrm{~g}$ every 12 hours with $1 \mathrm{~g}$ of aztreonam every 8 hours. Treatment was given for an average of 8 days. The primary outcome of these studies was clinical cure rate at test-ofcure visit in clinically evaluable and MITT populations. Secondary outcomes were microbiological response and clinical response at a test-of-cure visit at 8-15 days after the last dose of study drug and relapse/reinfection at a late 
follow up visit at 21-35 days after the last dose. Of 1396 randomized patients, 1378 received at least one dose of study drug; 1202 were clinically evaluable, and 914 were ME. The two groups were similar in demographic and infection data including sites of infection and area of involvement. In ME patients, S. aureus (MRSA and MSSA) was the most common pathogen.

The clinical cure rates in the evaluable groups were $91.6 \%$ for ceftaroline and $92.7 \%$ for vancomycin plus aztreonam (difference $-1.1 \%, 95 \% \mathrm{CI}$ : $-4.2 \%-2 \%$ ); in the MITT group the cure rates were $85.9 \%$ and $85.5 \%$, respectively (difference $0.3 \%, 95 \%$ CI: $-3.4 \%-4 \%$ ). Cure rates were also comparable in ME patients, $92.7 \%$ versus $94.4 \%$ (difference $-1.7 \%, 95 \% \mathrm{CI}:-4.9 \%-1.6 \%$ ). In bacteremic patients, cure rates were $84.6 \%$ in the ceftaroline group versus $100 \%$ in the vancomycin plus aztreonam group (difference $-15.4 \%, 95 \%$ CI: $-33.8 \%-1.5 \%$ ). This difference was not statistically significant. Of note there was a higher rate of S. aureus bacteremia (both MRSA and MSSA) in the ceftaroline group (18 vs 9).

\section{Ceftaroline: mode of action, microbiology, pharmacokinetics, safety, and tolerability Mode of action}

As with other $\beta$-lactam antibiotics, ceftaroline acts by binding penicillin-binding proteins (PBP) on the bacterial cell wall leading to perturbations in new wall formation as well as cell lysis. ${ }^{1}$ These PBPs have a variety of structures and functions and different bacteria have different PBPs. ${ }^{11}$ Ceftaroline was demonstrated after initial synthesis to have strong affinity for PBP 2a, a genetically altered PBP in MRSA. ${ }^{1}$ Further in vitro research has again demonstrated strong affinity for PBP 2a-conferring activity against MRSA, as well as a high affinity for PBPs 1a, 2b, 2x, and 3, which are important PBPs in MSSA and S. pneumoniae. ${ }^{12,13}$ These binding affinities were notably higher than those for oxacillin and ceftriaxone, standard antimicrobials for treatment of MSSA and S. pneumoniae, respectively.

\section{Microbiology}

Ceftaroline has a broad spectrum of activity which is represented in Table 1. Early in vitro testing demonstrated favorable minimum inhibitory concentration (MIC) against $S$. aureus, both MRSA and MSSA; S. epidermidis (methicillin-sensitive and -resistant strains); S. pneumoniae, including penicillin-resistant strains; and other streptococci.
Table I MIC ranges and MIC50-90 against selected pathogens. . $^{2,3,16-18,20-29,33,34}$

\begin{tabular}{|c|c|c|c|}
\hline Organism & MIC Range & MIC50 & MIC90 \\
\hline MSSA & $\leq 0.008-1$ & $0.12-0.25$ & $0.25-0.5$ \\
\hline MRSA & $0.12-4$ & $0.5-1$ & $0.5-2$ \\
\hline CONS & $\leq 0.008-4$ & $0.06-1$ & $0.12-2$ \\
\hline PSSP & $\leq 0.008-0.25$ & $\leq 0.008-0.015$ & $\leq 0.016-0.06$ \\
\hline PISP & $\leq 0.008-0.5$ & $0.015-0.13$ & $0.006-0.13$ \\
\hline PRSP & $\leq 0.008-0.5$ & $\leq 0.015-0.13$ & $0.12-0.5$ \\
\hline $\begin{array}{l}\beta \text {-hemolytic } \\
\text { streptococci }\end{array}$ & $\leq 0.008-0.12$ & $\leq 0.008-0.015$ & $\leq 0.015-0.03$ \\
\hline $\begin{array}{l}\text { Viridans group } \\
\text { streptococci }\end{array}$ & $\leq 0.008-16$ & $\leq 0.008-0.25$ & $0.03-1$ \\
\hline $\begin{array}{l}\text { Enterococcus } \\
\text { faecalis }^{a}\end{array}$ & $0.03->32$ & $\mathrm{I}-4$ & $4-16$ \\
\hline $\begin{array}{l}\text { Enterococcus } \\
\text { faecium }^{\mathrm{a}}\end{array}$ & $0.06->128$ & $I->64$ & $16->128$ \\
\hline Acinetobacter spp & $\leq 0.003->64$ & $2->64$ & $8->64$ \\
\hline $\begin{array}{l}\text { Citrobacter } \\
\text { freundii }\end{array}$ & $0.06-128$ & $0.12->16$ & $2-64$ \\
\hline Enterobacter spp ${ }^{\mathrm{b}}$ & $\leq 0.008->128$ & $\leq 0.12->32$ & $0.5->32$ \\
\hline Escherichia colib & $\leq 0.008->64$ & $0.06->32$ & $0.12->32$ \\
\hline Klebsiella spp ${ }^{\mathrm{b}}$ & $\leq 0.008->32$ & $0.06->32$ & $0.25->32$ \\
\hline Proteus spp & $\leq 0.03->32$ & $0.06->32$ & $0.12-64$ \\
\hline Salmonella spp & $0.06->32$ & $0.12-0.13$ & $0.25->32$ \\
\hline $\begin{array}{l}\text { Haemophilus } \\
\text { influenzae }\end{array}$ & $\leq 0.008-0.25$ & $\leq 0.008-0.12$ & $\leq 0.008-0.25$ \\
\hline $\begin{array}{l}\text { Moraxella } \\
\text { catarrhalis }\end{array}$ & $\leq 0.008-1$ & $0.03-0.25$ & $0.12-0.5$ \\
\hline $\begin{array}{l}\text { Pseudomonas } \\
\text { aeruginosa }\end{array}$ & $0.25->128$ & 16 & $>32$ \\
\hline Serratia marcescens & $0.015->128$ & $0.5-1$ & $2-32$ \\
\hline Bacteroides spp & $0.03->64$ & $8-64$ & $16->64$ \\
\hline Clostridium spp & $\leq 0.008-64$ & $0.06-2$ & $0.25-16$ \\
\hline Fusobacterium spp $^{d}$ & $\leq 0.008-64$ & $\leq 0.008-8$ & $0.06-32$ \\
\hline $\begin{array}{l}\text { Propionibacterium } \\
\text { acnes }\end{array}$ & $\leq 0.008-0.125$ & $\leq 0.008-0.03$ & 0.06 \\
\hline
\end{tabular}

Notes: ancludes vancomycin-susceptible and -resistant strains; bincludes cephalosporinsensitive and -resistant strains, as well as extended-spectrum $\beta$-lactamase-producing strains; 'includes $\beta$-lactamase positive and negative strains; ' ${ }^{\text {all }}$ isolates with MIC $>0.5$ are F. mortiferum.

Abbreviations: MIC, minimum inhibitory concentration; MIC50, MIC for $50 \%$ of isolates; MIC90, MIC for $90 \%$ of isolates; MSSA, methicillin-susceptible Staphylococcus aureus; MRSA, methicillin-resistant S. aureus; CONS, coagulase-negative Staphylococcus; PSSP, penicillin-sensitive Streptococcus pneumoniae; PISP, penicillin-intermediate S. pneumoniae; PRSP, penicillin-resistant S. pneumoniae; spp, species.

Gram-negative pathogens with favorable MICs include E. coli, Salmonella spp., K. oxytoca, K. pneumoniae, H. influenzae, and Moraxella catarrhalis. ${ }^{2}$ This spectrum has been confirmed against numerous pooled isolates in further in vitro testing., ${ }^{3,-21}$ Of note there is no activity against P. aeruginosa or extended spectrum $\beta$-lactamase (ESBL) producing Gram-negative organisms. ${ }^{3}$ Ceftaroline has also demonstrated in vitro efficacy against a number of anaerobic bacteria, largely Gram-positive and $\beta$-lactamase-negative Gram-negative organisms. ${ }^{22,23}$ It has been tested in several 
large samplings of pathogens causing CABP and ABSSSI with overall favorable results. ${ }^{24-28}$

One of the potential advantages of ceftaroline over other $\beta$-lactams is its activity against $S$. aureus isolates, including drug-resistant strains. In vitro testing against 152 strains of community-acquired MRSA from United States centers revealed the minimum inhibitory concentration required to inhibit the growth of $90 \%$ of organisms (MIC90) of ceftaroline to be $0.5 \mu \mathrm{g} / \mathrm{mL}$, a 64 -fold increase in potency over ceftriaxone. These strains all had Panton-Valentine leukocidin genes and $67.8 \%$ were USA300 strains. ${ }^{17}$ Activity of ceftaroline against MRSA and vancomycin-intermediate $S$. aureus has been confirmed in a hollow fiber model with ceftaroline demonstrating rapid bactericidal activity against these organisms. ${ }^{19}$ Further in vitro and in vivo testing has demonstrated activity against a broad range of $S$. aureus isolates including vancomycin-intermediate, vancomycinresistant, and daptomycin-nonsusceptible strains. ${ }^{29-32}$

Another therapeutic advantage of ceftaroline is its activity against a broad range of $S$. pneumoniae isolates, including penicillin-intermediate and -resistant strains. Initial in vitro testing demonstrated favorable MIC90 against penicillin-sensitive, -intermediate, and -resistant strains with ceftaroline MICs of $0.06 \mu \mathrm{g} / \mathrm{mL}, 0.13 \mu \mathrm{g} / \mathrm{mL}$, and $0.25 \mu \mathrm{g} / \mathrm{mL}$, respectively. These MICs are all favorable compared to ceftriaxone. ${ }^{2}$ Ceftaroline has demonstrated in vitro efficacy against $S$. pneumoniae strains resistant to penicillin, amoxicillin, erythromycin, and cefotaxime, ${ }^{15,33}$ showing superior in vitro activity to other $\beta$-lactams for cefotaxime-resistant strains. ${ }^{34}$ This superiority to ceftriaxone in resistant isolates has been demonstrated in vivo as well. ${ }^{35}$

\section{Pharmacokinetics}

Ceftaroline fosamil undergoes rapid dephosphorylation to the active drug after infusion. In a Phase I study of a single IV dose of ceftaroline to healthy subjects, a dose-proportional concentration was attained. ${ }^{36}$ In a 14 day IV dosing trial, the serum half-life of ceftaroline with $600 \mathrm{mg}$ every 12-hour dosing was 2.6 hours with a maximal concentration of $21 \mu \mathrm{g} / \mathrm{mL} .{ }^{37}$ Dosing in patients with decreased renal function has demonstrated an increase in half-life (up to 4.6 hours in those with creatinine clearance averaging $38 \mathrm{~mL} / \mathrm{min}$ ), similar maximal concentration $(31 \mu \mathrm{g} / \mathrm{mL})$, but greatly increased area under the curve (120 hours* $\mu \mathrm{g} / \mathrm{mL}$ versus 68 hours ${ }^{*} \mu \mathrm{g} / \mathrm{mL}$ in those with normal renal function). ${ }^{38}$ Therefore a dose reduction to $400 \mathrm{mg}$ every 12 hours is recommended for those with creatinine clearance between $30-50 \mathrm{~mL} / \mathrm{min} .{ }^{39}$ There are no data for those with creatinine clearance less than $30 \mathrm{~mL} / \mathrm{min}$ or those on hemodialysis. These pharmacokinetics have been confirmed with population data from the ABSSSI and CABP studies. ${ }^{40,41}$ In a posthoc analysis of drug-drug interactions, ceftaroline levels were found to be modestly elevated in patients receiving CYP1A2 inhibitors, CYP3A4/5/7 inhibitors, and anionic drugs undergoing active renal secretion, but the effects of these increased levels are unclear. ${ }^{42}$

\section{Safety and tolerability}

Integrated safety data from the two FOCUS and two CANVAS trials show comparable adverse event (AE) rates to the control groups. ${ }^{43,44}$ In the FOCUS studies, $47 \%$ of patients treated with ceftaroline had treatment-emergent AEs compared with $45.7 \%$ in the ceftriaxone group. Serious AEs were $11.3 \%$ versus $11.7 \%$, discontinuations $4.4 \%$ versus $4.1 \%$, and deaths $2.4 \%$ versus $2 \%$. Only one death in each treatment group was felt by investigators to be related to study drug. In the ceftaroline group the most common AEs were diarrhea (4.2\%), headache (3.4\%), and insomnia (3.1\%). There were more positive direct Coombs' tests in the ceftaroline group $(9.8 \%$ versus $4.5 \%)$, but no difference in rate of anemia $(0.8 \%$ versus $0.4 \%)$. Results were similar in the CANVAS trials with treatment-emergent AEs occurring in $44.7 \%$ of the ceftaroline group versus $47.5 \%$ of the vancomycin plus aztreonam group. Serious AEs were $4.3 \%$ versus $4.1 \%$. The most common AEs in those receiving ceftaroline were nausea $(5.9 \%)$, headache $(5.2 \%)$, diarrhea (4.9\%), and pruritis (3.5\%). Similar to FOCUS data, in the CANVAS groups $11.5 \%$ of ceftaroline had positive direct Coombs' tests complared with $4.3 \%$ in the comparator arm, but there was no hemolytic anemia in either group. Among all four studies there were only three cases of Clostridium difficile-associated diarrhea, all in CANVAS patients; two were in the ceftaroline group and one in the vancomycin plus aztreonam group.

\section{The advantages and disadvantages of ceftaroline in line with current therapy strategies}

The largest of ceftaroline's potential advantages over other agents, particularly other $\beta$-lactams, is its activity against MRSA, a pathogen that has had a recent steady increase in incidence ${ }^{45}$ as well as in antimicrobial resistance. ${ }^{46}$ Overall cases of MRSA infection doubled from 1999-2005 from 127,036 hospital admissions in 1999 to 278,203 in 2005. MRSA has increased from $43 \%$ of $S$. aureus infection to $58 \%$ over this time period. ${ }^{47}$ Based on active surveillance at 
several sites, in 2005 there were an estimated 94,360 cases of invasive MRSA infection in the United States with 18,650 deaths. ${ }^{48}$ A majority (58.4\%) of cases were community-onset in nature.

In the FOCUS studies, ceftaroline was compared headto-head with ceftriaxone, which is a preferred agent in the Infectious Diseases Society of America (IDSA)/American Thoracic Society guidelines for treatment of CABP (along with a macrolide for coverage of atypical organisms). ${ }^{49}$ In these noninferiority trials, ceftaroline was shown to be within the defined $-10 \%$ performance range of ceftriaxone overall, and therefore noninferior. While ceftaroline did have numeric superiority in several populations including those in most of the defined study groups and subgroups, ${ }^{8}$ given the design of these trials to test noninferiority and not superiority, ceftaroline cannot be called superior without further trials.

While not a traditional pathogen in CABP, MRSA is being recognized more and more frequently as a cause of severe pneumonia in otherwise healthy patients, as well as following influenza infection. ${ }^{50-53}$ Ceftaroline has a demonstrated bactericidal effect in MRSA pneumonia in animal studies. Early models demonstrated a colony count decrease of more than $99.9 \%$ in neutropenic mice with MRSA pneumonia when treatment with ceftaroline was started one day after infection compared with no significant change in colony counts with similar timing of linezolid or vancomycin. ${ }^{2}$ Of note, all three agents were equally effective when started only 2 hours after infection, but as MRSA is not a commonly thought of pathogen in CABP, directed anti-MRSA therapy is usually not initiated until following recovery of the organism. Further studies of ceftaroline for MRSA pneumonia are needed.

For ABSSSI, the current IDSA guidelines focus on Gram-positive coverage for cellulitis but specifically mention the growing problem of resistant $S$. aureus and $S$. pyogenes isolates in the selection of empiric therapy ${ }^{54}$ Indeed, in studies of microbiology of ABSSSI, MRSA is a predominant isolate. A prospective evaluation of patients with ABSSSI in an emergency department in northern California in 2003-2004 revealed over half to be infected with $S$. aureus; $75 \%$ of their staphylococcal isolates were MRSA. ${ }^{55}$ In Atlanta in 2003, 72\% of $S$. aureus isolates were MRSA; a majority of these were USA300 strains. ${ }^{56} \mathrm{~A} 2008$ prospective multicenter evaluation of purulent ABSSSI revealed $75 \%$ of these infections to be due to $S$. aureus, of which $79 \%$ were MRSA. $96 \%$ of these isolates were USA $300 .{ }^{57} \mathrm{As}$ in the FOCUStrials, the CANVAS trials were designed to demonstrate noninferiority, an aim at which they were successful. ${ }^{6,70}$ There is statistically significant improved outcome for ceftaroline over vancomycin plus aztreonam for ABSSSI in the United States study sites in the CANVAS 1 trial, but the trial had a small number of patients and the study was not designed for this particular outcome. Further testing particularly with USA300 infection is necessary. With Gram-negative-only infections, ceftaroline was statistically inferior with a cure rate of $85.3 \%$ versus $100 \%$, but again the study had small numbers and this outcome was outside the study design.

Ceftaroline has had limited clinical use to demonstrate development of antimicrobial resistance, but in vitro serial passage studies have shown limited resistance induced in multiple Gram-positive and Gram-negative pathogens. ${ }^{58}$ In this study no strains of $S$. pneumoniae or S. aureus demonstrated increased ceftaroline MIC after 50 daily serial passages. There was rare inducible resistance in $H$. influenzae and E. faecalis. There are no reports on development of resistance in the FOCUS and CANVAS trials.

Ceftaroline may eventually have a role in infections other than CABP and ABSSSI as well. Jacqueline et al initially demonstrated rapid bactericidal activity in vivo in a rabbit endocarditis model of infection due to MRSA and vancomycin-intermediate $S$. aureus (VISA), with comparable activity to vancomycin in MRSA infection and improved vegetation sterilization relative to vancomycin in VISA as well as favorable performance compared to linezolid in both strains ${ }^{59}$ More recently ceftaroline was compared with daptomycin and tigecycline in MSSA, MRSA, and glycopeptideintermediate $S$. aureus (GISA). Ceftaroline was superior to tigecycline and equivalent to daptomycin in vegetation sterilization for all isolates. ${ }^{30}$ Another animal study with ampicillin-sensitive $E$. faecalis endocarditis demonstrated improved bacterial killing and vegetation sterilization over vancomycin and linezolid in vancomycin-susceptible and vancomycin-resistant strains. ${ }^{60}$ Current guidelines recommend ampicillin or penicillin plus gentamicin for these infections ${ }^{61}$ These animal endocarditis studies may provide the basis for further clinical evaluation, though so far, data in humans are lacking.

Ceftaroline has also demonstrated superiority to vancomycin and comparableness to linezolid in treatment of rabbit osteomyelitis due to MRSA and GISA. ${ }^{62}$ Finally, ceftaroline has been shown to be superior to ceftriaxone in meningitis in rabbits due to penicillin-sensitive S. pneumoniae and a combination of ceftriaxone and vancomycin in penicillin-resistant S. pneumoniae. ${ }^{63}$ Current guidelines recommend the combination of vancomycin and a third-generation cephalosporin for initial therapy of bacterial meningitis due 
to $S$. pneumoniae ${ }^{64}$ Ceftaroline monotherapy may be further investigated for this application as well, though again, human data remain lacking to date.

One potential disadvantage of ceftaroline compared with other broad spectrum antibacterial agents is its lack of coverage of Gram-negative organisms, particularly those producing $\beta$-lactamases including AmpC, extended-spectrum $\beta$-lactamase (ESBL), and $K$. pneumoniae carbapenemase (KPC). ${ }^{19}$ Ceftaroline has been combined with a novel $\beta$-lactamase inhibitor, NXL104, with excellent in vitro susceptibility data for bacteria with these $\beta$-lactamases. This combination when tested in vivo demonstrated bactericidal activity in a mouse thigh infection model. ${ }^{65}$ Further pharmacodynamic modeling is being undertaken for the optimal dosing combination of these two agents. ${ }^{66}$ This promising combination also bears further investigation for treatment of these very challenging infections.

\section{Conclusion and place in therapy}

Ceftaroline has a promising role in the future of infectious diseases. It has been labeled the first new drug in the IDSA's " $10 \times$ ' 20 " initiative to have ten new antibiotics released by the year $2020 .{ }^{67}$ However, it has several obstacles to overcome prior to routine use over current guideline recommendations. At present it is approved only for CABP and ABSSSI and has demonstrated only noninferiority as opposed to superiority to its comparators. The lack of clinical trial data in patients with MRSA pneumonia and bacteremia separate from ABSSSI and $\mathrm{CABP}$ in particular make it difficult to recommend ceftaroline over alternative therapies. Until there is more significant clinical experience, it can at least be counted among the dwindling array of options clinicians have to fight these increasingly resistant routine infections. Ceftaroline's potential for treatment of invasive infections due to MRSA and other resistant organisms is tantalizing and bears more investigation. It is hoped further clinical studies will illuminate the question mark looming over this otherwise promising new drug.

\section{Disclosure}

The authors report no conflicts of interest in this work.

\section{References}

1. Ishikawa T, Matsunaga N, Tawada H, et al. TAK-599, a novel N-phosphono type prodrug of anti-MRSA cephalosporin T-91825: synthesis, physicochemical and pharmacological properties. Bio Org Med Chem. 2003;11(11):2427-2437.

2. Iizawa $Y$, Nagai J, Ishikawa $T$, et al. In vitro antimicrobial activity of T-91825, a novel anti-MRSA cephalosporin, and in vivo anti-MRSA activity of its prodrug, TAK-599. J Infect Chemother. 2004;10(3): 146-156.
3. Sader HS, Fritsche TR, Kaniga K, Ge Y, Jones RN. Antimicrobial activity and spectrum of PPI-0903M (T-91825), a novel cephalosporin, tested against a worldwide collection of clinical strains. Antimicrob Agents Chemother. 2005;49(8):3501-3512.

4. File TM, Low DE, Eckburg PB, et al. FOCUS 1: a randomized, double-blinded, multicentre, Phase III trial of the efficacy and safety of ceftaroline fosamil versus ceftriaxone in community-acquired pneumonia. J Antimicrob Chemother. 2011;66 Suppl 3:iii19-iii32.

5. Low DE, File TM, Eckburg PB, et al. FOCUS 2: a randomized, double-blinded, multicentre, Phase III trial of the efficacy and safety of ceftaroline fosamil versus ceftriaxone in community-acquired pneumonia. J Antimicrob Chemother. 2011;66 Suppl 3:iii33-iii44.

6. Corey GR, Wilcox MH, Talbot GH, et al. CANVAS 1: the first Phase III, randomized, double-blind study evaluating ceftaroline fosamil for the treatment of patients with complicated skin and skin structure infections. J Antimicrob Chemother. 2010;65 Suppl 4:iv41-iv51.

7. Wilcox MH, Corey GR, Talbot GH, et al. CANVAS 2: the second Phase III, randomized, double-blind study evaluating ceftaroline fosamil for the treatment of patients with complicated skin and skin structure infections. J Antimicrob Chemother. 2010;65 Suppl 4:iv53-iv65.

8. File TM Jr, Low DE, Eckburg PB, et al. Integrated analysis of FOCUS 1 and FOCUS 2: randomized, doubled-blinded, multicenter phase 3 trials of the efficacy and safety of ceftaroline fosamil versus ceftriaxone in patients with community-acquired pneumonia. Clin Infect Dis. 2010;51(12):1395-1405.

9. Talbot GH, Thye D, Das A, Ge Y. Phase 2 study of ceftaroline versus standard therapy in treatment of complicated skin and skin structure infections. Antimicrob Agents Chemother. 2007;51(10): 3612-3616.

10. Corey GR, Wilcox M, Talbot GH, et al. Integrated analysis of CANVAS 1 and 2: phase 3, multicenter, randomized, double-blind studies to evaluate the safety and efficacy of ceftaroline versus vancomycin plus aztreonam in complicated skin and skin-structure infection. Clin Infect Dis. 2010;51(6):641-650.

11. Ghuysen JM. Molecular structures of penicillin-binding proteins and ß-lactamases. Trends Microbiol. 1994;2(10):372-380.

12. Moisan H, Pruneau M, Malouin F. Binding of ceftaroline to penicillinbinding proteins of Staphylococcus aureus and Streptococcus pneumoniae. J Antimicrob Chemother. 2010;65(4):713-716.

13. Kosowska-Shick K, McGhee P, Appelbaum P. Affinity of ceftaroline and other $\beta$-lactams for penicillin-binding proteins from Staphylococcus aureus and Streptococcus pneumoniae. Antimicrob Agents Chemother. 2010;54(5):1670-1677.

14. Mushtaq S, Warner M, Ge Y, Kaniga K, Livermore DM. In vitro activity of ceftaroline (PPI-0903M, T-91825) against bacteria with defined resistance mechanisms and phenotypes. $J$ Antimicrob Chemother. 2007;60(2):300-311.

15. Fenoll A, Aguilar L, Robledo O, et al. In vitro activity of ceftaroline against Streptococcus pneumoniae isolates exhibiting resistance to penicillin, amoxicillin, and cefotaxime. Antimicrob Agents Chemother. 2008;52(11):4209-4210.

16. Ge Y, Biek D, Talbot GH, Sahm DF. In vitro profiling of ceftaroline against a collection of recent bacterial clinical isolates from across the United States. Antimicrob Agents Chemother. 2008;52(9): 3398-3407.

17. Sader HS, Fritsche TR, Jones RN. Antimicrobial activities of ceftaroline and ME1036 tested against clinical strains of community-acquired methicillin-resistant Staphylococcus aureus. Antimicrob Agents Chemother. 2008;52(3):1153-1155.

18. Brown SD, Traczewski MM. In vitro antimicrobial activity of a new cephalosporin, ceftaroline, and determination of quality control ranges for MIC testing. Antimicrob Agents Chemother. 2009;53(3): $1271-1274$

19. Vidaillac C, Leonard SN, Rybak MJ. In vitro activity of ceftaroline against methicillin-resistant Staphylococcus aureus and heterogeneous vancomycin-intermediate $S$. aureus in a hollow fiber model. Antimicrob Agents Chemother. 2009;53(11):4712-4717. 
20. Richter SS, Heilmann KP, Dohrn CL, et al. Activity of ceftaroline and epidemiologic characterization of Staphylococcus aureus from 43 medical centers in the United States, 2009. Antimicrob Agents Chemother. 2011;55(9):4154-4160.

21. Karlowsky JA, Adam HJ, DeCorby MR, Lagacé-Wiens PRS, Hoban DJ, Zhanel GG. In vitro activity of ceftaroline against Gram-positive and Gram-negative pathogens isolated from patients attending Canadian hospitals in 2009. Antimicrob Agents Chemother. 2011;55(6): 2837-2846.

22. Citron DM, Tyrrell K, Merriam CV, Goldstein EJ. In vitro activity of ceftaroline against 623 diverse strains of anaerobic bacteria. Antimicrob Agents Chemother. 2010;54(4):1627-1632.

23. Snydman DR, Jacobus NV, McDermott LA. In vitro activity of ceftaroline against a broad spectrum of recent clinical anaerobic isolates. Antimicrob Agents Chemother. 2010;55(1):421-425.

24. Morrissey I, Ge Y, Janes R. Activity of the new cephalosporin ceftaroline against bacteraemia isolates from patients with community-acquired pneumonia. Int J Antimicrob Agents. 2009;33(6):515-519.

25. Jones RN, Mendes RE, Sader HS. Ceftaroline activity against pathogens associated with complicated skin and skin structure infections: results from an international surveillance study. $J$ Antimicrob Chemother. 2010;65 Suppl 4:iv17-iv31.

26. Jacobs MR, Good CE, Windau AR, et al. Activity of ceftaroline against recent emerging serotypes of Streptococcus pneumoniae in the USA Antimicrob Agents Chemother. 2010;54(6):2716-2719.

27. Jones RN, Farrell DJ, Mendes RE, Sader HS. Comparative ceftaroline activity tested against pathogens associated with communityacquired pneumonia: results from an international surveillance study J Antimicrob Chemother. 2011;66 Suppl 3:iii69-iii80.

28. Critchley IA, Eckburg PB, Jandourek A, Biek D, Friedland HD, Thye DA. Review of ceftaroline fosamil microbiology: integrated FOCUS studies. J Antimicrob Chemother. 2011;66 Suppl 3: iii45-iii51.

29. Saravolatz L, Pawlak J, Johnson L. In vitro activity of ceftaroline against community-associated methicillin-resistant, vancomycinintermediate, vancomycin-resistant, and daptomycin-nonsusceptible Staphylococcus aureus isolates. Antimicrob Agents Chemother. 2010; 54(7):3027-3030.

30. Jacqueline C, Amador G, Batard E, et al. Comparison of ceftaroline fosamil, daptomycin and tigecycline in an experimental rabbit endocarditis model caused by methicillin-susceptible, methicillin-resistant and glycopeptide-intermediate Staphylococcus aureus. J Antimicrob Chemother. 2011;66(4):863-866.

31. Zhanel GG, Rossnagel E, Nichol K, et al. Ceftaroline pharmacodynamic activity versus community-associated and healthcare-associated methicillin-resistant Staphylococcus aureus, heteroresistant vancomycinintermediate $S$. aureus, vancomycin-intermediate $S$. aureus and vancomycin-resistant $S$. aureus using an in vitro model. J Antimicrob Chemother. 2011;66(6):1301-1305.

32. Steed M, Vidaillac C, Rybak MJ. Evaluation of ceftaroline activity versus daptomycin (DAP) against DAP-nonsusceptible methicillinresistant Staphylococcus aureus strains in an in vitro pharmacokinetic/ pharmacodynamic model. Antimicrob Agents Chemother. 2011; 55(7):3522-3526.

33. Patel SN, Pillai DR, Pong-Porter S, McGeer A, Green K, Low DE. In vitro activity of ceftaroline, ceftobiprole and cethromycin against clinical isolates of Streptococcus pneumoniae collected from across Canada between 2003 and 2008. JAntimicrob Chemother. 2009;64(3): 659-660.

34. McGee L, Biek D, Ge Y, et al. In vitro evaluation of the antimicrobial activity of ceftaroline against cephalosporin-resistant isolates of Streptococcus pneumoniae. Antimicrob Agents Chemother. 2009;53(2): 552-556.

35. Croisier-Bertin D, Piroth L, Charles PE, et al. Ceftaroline versus ceftriaxone in a highly penicillin-resistant pneumococcal pneumonia rabbit model using simulated human dosing. Antimicrob Agents Chemother 2011;55(7):3557-3563.
36. Ge Y, Floren L, Redman R, Wikler M, Liao S. Single-dose pharmacokinetics (PK) of ceftaroline (PPI-0903) in healthy subjects. 46th Interscience Conference on Antimicrobial Agents and Chemotherapy; September 27-30, 2006; San Francisco, CA. Abstract A-1936.

37. Ge Y, Redman R, Floren L, Liao S, Wikler M. The pharmacokinetics (PK) and safety of ceftaroline (PPI-0903) in healthy subjects receiving multiple-dose intravenous (IV) infusions. 46th Interscience Conference on Antimicrobial Agents and Chemotherapy; September 27-30, 2006; San Francisco, CA. Abstract A-1937.

38. Ge Y, Thye D, Liao S, Talbot G. Pharmacokinetics (PK) of ceftaroline (PPI-0903) in subjects with mild or moderate renal impairment (RI). 46th Interscience Conference on Antimicrobial Agents and Chemotherapy; September 27-30, 2006; San Francisco, CA. Abstract A-1939.

39. Ge Y, Liao S, Thye DA, Talbot GH. Ceftaroline (CPT) dose adjustment recommendations for subjects with mild or moderate renal impairment (RI). 47th Interscience Conference on Antimicrobial Agents and Chemotherapy; September 17-20, 2007; Chicago, IL. Abstract A-35.

40. Ge Y, Liao S, Talbot GH. Population pharmacokinetics (PK) analysis of ceftaroline (CPT) in volunteers and patients with complicated skin and skin structure infection (cSSSI). 47th Interscience Conference on Antimicrobial Agents and Chemotherapy; September 17-20, 2007; Chicago, IL. Abstract A-34.

41. Van Wart SA, Forrest A, Khariton T, et al. Population pharmacokinetic analysis of ceftaroline in patients with complicated skin and skin structure infection or community-acquired pneumonia. 51st Interscience Conference on Antimicrobial Agents and Chemotherapy; September 17-20, 2011; Chicago, IL. Abstract A2-547.

42. Van Wart SA, Reynolds DK, Khariton T, et al. Impact of concomitant medication use on the pharmacokinetics of ceftaroline in patients with complicated skin and skin structure infections or community-acquired pneumonia. 51st Interscience Conference on Antimicrobial Agents and Chemotherapy; September 17-20, 2011; Chicago, IL. Abstract A2-548.

43. Corrado ML. Integrated safety summary of CANVAS 1 and 2 trials: Phase III, randomized, double-blind studies evaluating ceftaroline fosamil for the treatment of patients with complicated skin and skin structure infections. J Antimicrob Chemother. 2010;65 Suppl 4:iv67-iv71.

44. Rank DR, Friedland HD, Laudano JB. Integrated safety summary of FOCUS 1 and FOCUS 2 trials: Phase III randomized, double-blind studies evaluating ceftaroline fosamil for the treatment of patients with community-acquired pneumonia. J Antimicrob Chemother. 2011; 66 Suppl 3:iii53-iii59.

45. Boucher HW, Corey GR. Epidemiology of methicillin-resistant Staphylococcus aureus. Clin Infect Dis. 2008;46 Suppl 5:S344-S349.

46. Sakoulas G, Moellering RC. Increasing antibiotic resistance among methicillin-resistant Staphylococcus aureus strains. Clin Infect Dis. 2008;46 Suppl 5:S360-S367.

47. Klein E, Smith DL, Laxminarayan R. Hospitalizations and deaths caused by methicillin-resistant Staphylococcus aureus, United States, 1999-2005. Emerg Infect Dis. 2007;13(12):1840-1846.

48. Klevens RM, Morrison MA, Nadle J, et al. Invasive methicillinresistant Staphylococcus aureus infections in the United States. JAMA 2007;298(15):1763-1771

49. Mandell LA, Wunderink RG, Anzueto A, et al. Infectious Diseases Society of America/American Thoracic Society consensus guidelines on the management of community-acquired pneumonia in adults. Clin Infect Dis. 2007;44 Suppl 2:S27-S72.

50. Francis JS, Doherty MC, Lopatin U, et al. Severe community-onset pneumonia in healthy adults caused by methicillin-resistant Staphylococcus aureus carrying the Panton-Valentine leukocidin genes. Clin Infect Dis. 2005;40(1):100-107.

51. Rubinstein E, Kollef MH, Nathwani D. Pneumonia caused by methicillin-resistant Staphylococcus aureus. Clin Infect Dis. 2008; 46 Suppl 5:S378-S385.

52. Hidron AI, Low CE, Honig EG, Blumberg HM. Emergence of community-acquired meticillin-resistant Staphylococcus aureus strain USA 300 as a cause of necrotising community-onset pneumonia. Lancet Infect Dis. 2009;9(6):384-392. 
53. Defres S, Marwick C, Nathwani D. MRSA as a cause of lung infection including airway infection, community-acquired pneumonia and hospital-acquired pneumonia. Eur Respir J. 2009;34(6):1470-1476.

54. Stevens DL, Bisno AL, Chambers HF, et al. Practice guidelines for the diagnosis and management of skin and soft-tissue infections. Clin Infect Dis. 2005;41(10):1373-1406.

55. Frazee BW, Lynn J, Charlebois ED, Lambert L, Lowery D, PerdreauRemington F. High prevalence of methicillin-resistant Staphylococcus aureus in emergency department skin and soft tissue infections. Ann Emerg Med. 2005;45(3):311-320.

56. King MD, Humphrey BJ, Wang YF, Kourbatova EV, Ray SM, Blumberg HM. Emergence of community-acquired methicillin-resistant Staphylococcus aureus USA 300 clone as the predominant cause of skin and soft-tissue infections. Ann Intern Med. 2006;144(5):309-317.

57. Talan DA, Krishnadasan A, Gorwitz RJ, et al. Comparison of Staphylococcus aureus from skin and soft-tissue infections in US emergency department patients, 2004 and 2008. Clin Infect Dis. 2011;53(2):144-149.

58. Clark C, McGhee P, Appelbaum PC, Kosowska-Shick K. Multistep resistance development studies of ceftaroline in Gram-positive and -negative bacteria. Antimicrob Agents Chemother. 2011;55(5): 2344-2351.

59. Jacqueline C, Caillon J, Le Mabecque V, et al. In vivo efficacy of ceftaroline (PPI-0903), a new broad-spectrum cephalosporin, compared with linezolid and vancomycin against methicillin-resistant and vancomycin-intermediate Staphylococcus aureus in a rabbit endocarditis model. Antimicrob Agents Chemother. 2007;51(9):3397-3400.

60. Jacqueline C, Caillon J, Batard E, et al. Evaluation of the in vivo efficacy of intramuscularly administered ceftaroline fosamil, a novel cephalosporin, against a methicillin-resistant Staphylococcus aureus strain in a rabbit endocarditis model. J Antimicrob Chemother. 2010;65(10):2264-2265.
61. Baddour LM, Wilson WR, Bayer AS, et al. Infective endocarditis: diagnosis, antimicrobial therapy, and management of complications: a statement for healthcare professionals from the Committee on Rheumatic Fever, Endocarditis, and Kawasaki Disease, Council on Cardiovascular Disease in the Young, and the Councils on Clinical Cardiology, Stroke, and Cardiovascular Surgery and Anesthesia, American Heart Association: endorsed by the Infectious Diseases Society of America. Circulation. 2005;111(23):e394-e434.

62. Jacqueline C, Amador G, Caillon J, et al. Efficacy of the new cephalosporin ceftaroline in the treatment of experimental methicillinresistant Staphylococcus aureus acute osteomyelitis. J Antimicrob Chemother. 2010;65(8):1749-1752.

63. Cottagnoud P, Acosta F, Biek D, Cottagnoud M, Lieb S. Efficacy of ceftaroline fosamil against penicillin-sensitive and -resistent Streptococcus pneumoniae in an experimental rabbit meningitis model. 50th Interscience Conference on Antimicrobial Agents and Chemotherapy; September 12-15, 2010; Boston, MA. Abstract B-702.

64. Tunkel AR, Hartman BJ, Kaplan SL, et al. Practice guidelines for the management of bacterial meningitis. Clin Infect Dis. 2004;39(9): 1267-1284.

65. Wiskirchen DE, Crandon JL, Furtado GH, Williams G, Nicolau DP. In Vivo efficacy of a human-simulated regimen of ceftaroline combined with NXL104 against extended-spectrum- $\beta$-lactamase (ESBL)Producing and non-ESBL-producing Enterobacteriaceae. Antimicrob Agents Chemother. 2011;55(7):3220-3225.

66. Louie A, Castanheira M, Liu W, et al. Pharmacodynamics of $\beta$-lactamase inhibition by NXL104 in combination with ceftaroline, examining organisms with multiple types of $\beta$-lactamases. Antimicrob Agents Chemother. 2012;56(1):258-270.

67. Infectious Diseases Society of America. The $10 \mathrm{x}$ ' 20 initiative: pursuing a global commitment to develop 10 new antibacterial drugs by 2020 . Clin Infect Dis. 2010;50(8):1081-1083.
Therapeutics and Clinical Risk Management

\section{Publish your work in this journal}

Therapeutics and Clinical Risk Management is an international, peerreviewed journal of clinical therapeutics and risk management, focusing on concise rapid reporting of clinical studies in all therapeutic areas, outcomes, safety, and programs for the effective, safe, and sustained use of medicines. This journal is indexed on PubMed Central, CAS,

\section{Dovepress}

EMBase, Scopus and the Elsevier Bibliographic databases. The manuscript management system is completely online and includes a very quick and fair peer-review system, which is all easy to use. Visit http://www.dovepress.com/testimonials.php to read real quotes from published authors. 